\title{
Assessment of the Combined Use of Basic Oxygen Furnace Sludge and Hydrogen Peroxide in the Treatment of Acid Mine Drainage
}

Sandrine F. Araujo

Universidade Federal de Minas Gerais

Cláudia L. Caldeira

Universidade Federal de Minas Gerais

Virgínia S.T. Ciminelli

Universidade Federal de Minas Gerais

Ricardo P. Borba

Universidade Estadual de Campinas

Joanna P. Rodrigues

Universidade Federal de Minas Gerais

Gustavo F. Simões ( $\nabla$ gustavo@desa.ufmg.br)

Universidade Federal de Minas Gerais https://orcid.org/0000-0001-5538-5292

Research Article

Keywords:

Posted Date: February 15th, 2021

DOl: https://doi.org/10.21203/rs.3.rs-164951/v1

License: (9) (i) This work is licensed under a Creative Commons Attribution 4.0 International License.

Read Full License 
ASSESSMENT OF THE COMBINED USE OF BASIC OXYGEN FURNACE SLUDGE AND HYDROGEN PEROXIDE IN THE TREATMENT OF ACID MINE DRAINAGE

Sandrine F. Araujo ${ }^{1}$; Cláudia L. Caldeira ${ }^{2}$; Virgínia S.T. Ciminelli2,3 ; Ricardo P. Borba ${ }^{4}$; Joanna P.

Rodrigues $^{1}$;Gustavo F. Simões ${ }^{1 *}$

${ }^{1}$ Department of Sanitary and Environmental Engineering, Universidade Federal de Minas Gerais, UFMG, Av. Antônio Carlos, 6627, Belo Horizonte - MG, Brazil, 31270-901.

${ }^{2}$ Department of Metallurgical and Materials Engineering, Universidade Federal de Minas Gerais, UFMG. Brazil.

${ }^{3}$ National Institute of Science and Technology: INCT- Acqua, Brazil.

${ }^{4}$ Department of Geology and Natural Resources. Universidade Estadual de Campinas, UNICAMP. Brazil.

* Corresponding author e-mail: gustavo@desa.ufmg.br phone: +55 31 3409-1792. Fax: +55 31 34091879.

Acknowledgments: The authors would like to thank Filipe A. T. Alves and Patricia Lopes at LAQDEMET/UFMG for performing the ICP-OES analyses. The authors would also like to thank the Center of Microscopy at University of the state of Minas Gerais (http://www.microscopia.ufmg.br) for providing the equipment and technical support for the experiments involving water analysis and electron microscopy; the Foundation of Support and Research of the state of Minas Gerais (FAPEMIG); the Coordination of Superior Level Staff Improvement (CAPES) and the National Council for Scientific and Technological Development (CNPq) for their support during this research.

ABSTRACT -We recently demonstrated the use of basic oxygen furnace sludge (BOFS) to remove arsenic and sulfate from acidic solutions, which was found to be an interesting alternative for the reuse of steel waste. In this study, four systems were evaluated to determine whether BOFS is stable in acidic solutions and capable of removing As, Mn, and sulfate from acid mine drainage (AMD). In the S1 system (BOFS/DEIONIZED WATER pH 2.5), the stability of the residue was evaluated by placing the BOFS in 
deionized water acidified with $\mathrm{H}_{2} \mathrm{SO}_{4}$ until the $\mathrm{pH}$ reached 2.5. This system was maintained for $408 \mathrm{~h}$ under agitation to evaluate the possible solubilization of metals present in the BOFS. The results showed that only $\mathrm{Ca}$ and $\mathrm{Mg}$ were solubilized, and the $\mathrm{pH}$ increased from 2.5 to 12 after $408 \mathrm{~h}$. The $\mathrm{S} 3$ system (BOFS/AMD) evaluated the metal removal capacity by BOFS and achieved $100 \%$ removal of As and Mn and $70 \%$ removal of sulfate after $648 \mathrm{~h}$. In the first $30 \mathrm{~min}$, the $\mathrm{pH}$ increased from 2.5 to 9.0 , which was maintained until the end of the experiment. Simultaneously, $\mathrm{S} 4$ and $\mathrm{S} 5$ systems (BOFS/AMD / $\mathrm{H}_{2} \mathrm{O}_{2}$ ) were also evaluated using the oxidizing agent $\mathrm{H}_{2} \mathrm{O}_{2}(29 \% \mathrm{w} / \mathrm{w})$ in the following proportions: $0.5 \mathrm{mM}$ in $\mathrm{S} 4$ and $1 \mathrm{mM}$ in S5. The removal of As, Mn, and sulfate in these systems was similar to that in the S3 system, which contained only BOFS. The results demonstrated that the formation of iron oxides was not accelerated by $\mathrm{H}_{2} \mathrm{O}_{2}$ and that iron, which is present in high concentrations in BOFS, was not the primary agent influencing metal removal from AMD.

Keywords: basic oxygen furnace sludge (BOFS), steel waste reuse, arsenic removal, sulfate removal, passive treatment

\section{INTRODUCTION}

Acid mine drainage (AMD) presents serious environmental pollution problems due to its high acidity and high concentrations of $\mathrm{As}^{3+}, \mathrm{As}^{5+}, \mathrm{Pb}^{2+}, \mathrm{Cu}^{2+}, \mathrm{Zn}^{2+}, \mathrm{Mn}^{2+}, \mathrm{Fe}^{2+} / \mathrm{Fe}^{3+}$, and $\mathrm{Cd}^{2+}$ ad sulfate (Skousen et al. 2000). Because of its corrosive nature, AMD interacts with rocks, which contain different metals, thus facilitating metal solubility. Hence, AMD can facilitate the accumulation of high concentrations of dissolved metals in receiving waters and negatively affect biota (Kefeni et al. 2017).

Over the past 50 years, significant effort has been made to reduce the impact of AMD on the environment by removing metals and sulfate via neutralization, primarily using industrial chemicals. The most popular chemicals commonly used for neutralization include limestone $\left(\mathrm{CaCO}_{3}\right)$, hydrated lime $\left(\mathrm{Ca}(\mathrm{OH})_{2}\right)$, and lime $(\mathrm{CaO})$. These processes collectively consume protons and produce alkalinity, thereby reducing the impacts of AMD (Mayes et al. 2009).

Technologies that use zero valente iron $\left(\mathrm{Fe}^{0} ; \mathrm{ZVI}\right)$ have been successful in removing dissolved metals. Corrosion products from $\mathrm{Fe}^{0}$ such as $\mathrm{Fe}(\mathrm{OH})_{2}, \mathrm{Fe}(\mathrm{OH})_{3}$, lepidocrocite $(\gamma-\mathrm{FeOOH})$, maghemite $\left(\gamma-\mathrm{Fe}_{2} \mathrm{O}_{3}\right)$, magnetite $\left(\mathrm{Fe}_{3} \mathrm{O}_{4}\right)$, and hematite $\left(\mathrm{Fe}_{2} \mathrm{O}_{3}\right)$ are important in the removal of various contaminants (Satapanajaru et al. 2003) through adsorption and co-precipitation mechanisms. The formation of these 
oxyhydroxides depends on the $\mathrm{pH}$ and availability of $\mathrm{O}_{2}$ in the system. In the $\mathrm{pH}$ range of natural waters, $\mathrm{Fe}^{2+}$ can hydrolyze and form $\mathrm{Fe}(\mathrm{OH})_{2}$ on the surface of ZVI (Eq. 1). $\mathrm{Fe}^{2+}$ has limited stability and is sensitive to the presence of molecular oxygen $\left(\mathrm{O}_{2}\right)$. The oxidation of $\mathrm{Fe}^{2+}$ species due to the presence of $\mathrm{O}_{2}$ is rapid, and the reaction rate increases as $\mathrm{pH}$ increases. Depending on the availability of $\mathrm{O}_{2}$, various oxyhydroxides such as $\mathrm{Fe}_{3} \mathrm{O}_{4}, \mathrm{Fe}(\mathrm{OH})_{3}$, and $\mathrm{FeOOH}$ are generated (Eq. 2-4) (Guan et al. 2015).

$\mathrm{Fe}^{2+}+2 \mathrm{H}_{2} \mathrm{O} \rightarrow \mathrm{Fe}(\mathrm{OH})_{2} \downarrow+2 \mathrm{H}^{+}$

$6 \mathrm{Fe}^{2+}+\mathrm{O}_{2}+6 \mathrm{H}_{2} \mathrm{O} \rightarrow 2 \mathrm{Fe}_{3} \mathrm{O}_{4} \downarrow+12 \mathrm{H}^{+}$

$4 \mathrm{Fe}^{2+}+\mathrm{O}_{2}+10 \mathrm{H}_{2} \mathrm{O} \rightarrow 4 \mathrm{Fe}(\mathrm{OH})_{3} \downarrow+8 \mathrm{H}^{+}$

$4 \mathrm{Fe}^{2+}+\mathrm{O}_{2}+6 \mathrm{H}_{2} \mathrm{O} \rightarrow 4 \mathrm{FeOOH} \downarrow+8 \mathrm{H}^{+}$

The aging process of oxy-hydroxides is usually accompanied by dehydration and conversion in less porous structures (Anderson and Benjamin 1985), leading to serious problems such as corrosive passivation (loss of reactivity), i.e., the slow kinetics of $\mathrm{Fe}^{0}$ corrosion water and the subsequent low efficiency to remove target contaminants (Guo et al. 2016). When the $\mathrm{Fe}^{0}$ surface is activated by oxidizing agents such as $\mathrm{KMnO}_{4}, \mathrm{NaClO}$, and $\mathrm{H}_{2} \mathrm{O}_{2}$ (Guo et al. 2008, Guo et al. 2016, Li et al. 2018, Yang et al. 2016), the oxidation process is continuous, thus increasing metal removal efficiency. Iron-rich materials including $\mathrm{Fe}^{0}$, as alkaline industrial by-products that have been treated as waste, have been studied recently for AMD remediation. The most common alkaline industrial products tested for AMD treatments are cement kiln dust, lime kiln dust, red bauxite sludge, coal fly ash, and blast furnace slag. By-products from quicklime manufacturing were used instead of commercial quicklime or slaked lime, which are traditionally applied as neutralizing chemicals for AMD treatment (Tolonen et al. 2014). The residual sludge produced by washing the gas system from the blast furnace slag as well as fine solid particles recovered after the wet washing of gases generated from the basic oxygen furnace (BOF) are known as residual gas sludge (BOFS). These types of sludge have been reported as among the most effective materials for treating AMD (Jafaripour et al. 2015).

Recently, Araujo et al. (2019) proposed the use of BOFS to remove arsenic and sulfate in an acidic solution ( $\mathrm{pH} 2.5$ ). It was found that although BOFS contains $50 \% \mathrm{Fe}^{0}$, the primary mechanism for removing arsenic and sulfate was calcium-mediated precipitation, with no species of As adsorbed or precipitated in the form of iron oxy-hydroxides. According to the authors, the iron oxides present in the system may not have been efficient in removing contaminants due to the formation of a passive layer of iron oxides/hydroxides on the surface of the ZVI. 
The objective of this study was to demonstrate the ability of BOFS in removing metals (As, Mn, and $\mathrm{Mg}$ ) and sulfate present in actual AMD and evaluate whether combining an oxidizing agent $\left(\mathrm{H}_{2} \mathrm{O}_{2}\right)$ with BOFS increases metal removal efficiency through the continuous oxidation of ZVI.

\section{MATERIALS AND METHODS}

\subsection{Characterization of BOFS}

BOFS was collected from a gas-washing system in a melt shop during steel production via an oxygen converter or Linz-Donawitz (LD) process. Approximately $200 \mathrm{~kg}$ of BOFS was collected and divided into $20-\mathrm{kg}$ samples, which were dried on plates at $70^{\circ} \mathrm{C}$ for $24 \mathrm{~h}$. The samples were further separated into $50 \mathrm{~g}$ portions, which were sealed in plastic bags and stored in a dry place during the entire study period. Chemical analyses of the BOFS were performed using aqua regia. In the aqua regia digestion method, the sample was digested in concentrated acid $\left(1: 3 \mathrm{HNO}_{3} / \mathrm{HCl}\right)$ and, then, placed in a digester block for $2 \mathrm{~h}$ at $\sim 80{ }^{\circ} \mathrm{C}$. The fused sample was, then, dissolved in a $10 \% \mathrm{v} / \mathrm{v} \mathrm{HNO}_{3}$ solution and analyzed by inductively coupled plasma optical emission spectrometry (ICP-OES; Perkin Elmer Optima 7300DV) according to the conditions described in Tables S1 and S2.

Total carbon and sulfur were determined using a LECO SC632 sulfur carbon. BOFS toxicity was determined according to the Brazilian standard (ABNT 2004), which classifies solid waste according to its toxicity. The crystalline phases were identified by X-ray diffraction (XRD) using a Rigaku diffractometer (Geiger-Flex 2037) with radiation $\mathrm{CuKa}=1,54051 \AA$ A. Scanning electron microscopy (SEM) and energy dispersive spectroscopy (EDS) were performed using an FEI Quanta 200 field emission gun scanning electron microscope. The identification and quantification of the iron phases present in the BOFS were performed using Mossbaüer spectroscopy in a conventional Mossbaüer spectrophotometer (constant acceleration, source of 57 Co in Rh matrix, using $\alpha$-Fe as the standard). The granulometry of the samples was analyzed by a laser diffraction particle size distribution analyzer (Horiba LA-950).

\subsection{Characterization of aqueous samples}

AMD was collected from a gold mine in Minas Gerais, Brazil. The collected volume (200 L) was stored in high-density polyethylene drums in a cold chamber until analysis. Deionized water was also characterized and the results are shown in Table S3. 
The $\mathrm{pH}$ electrode (HACH 2000) was calibrated using National Institute of Standards and Technology (NIST) traceable $\mathrm{pH}$ of 2.0, 4.0, 7.0, and 10.0 buffers and the oxidation-reduction potential (ORP) electrode (InLab Redox Ag with reference electrolyte $3 \mathrm{~mol} / \mathrm{L} \mathrm{KNO}_{3}$; Mettler Toledo) reported in relation to the standard hydrogen electrode (SHE) which forms the basis of the thermodynamic scale of oxidation-reduction potentials (Langmuir 1971) and conductivity (Hanna HI 9835). Aqueous samples were analyzed using an inductively coupled mass spectrometer (ICP-OES)—Perkin Elmer Optima 7300DV.

2.3 Stability and removal of metals by BOFS and $\mathrm{BOFS} / \mathrm{H}_{2} \mathrm{O}_{2}-$ batch tests

The conditions proposed in each system are shown in Table 1.

Table 1- Evaluated systems containing BOFS

\begin{tabular}{ccccccc}
\hline ID & \multicolumn{2}{c}{ System (S/L)* } & BOFS $(\mathrm{g})$ & Solution $(\mathrm{mL})$ & Ratio S/L $(\mathrm{g} / \mathrm{L})$ & $\mathrm{pH}$ \\
\hline S1 & BOFS & Deionized water & 1 & 40 & $25: 1$ & 2.5 \\
S3 & BOFS & AMD & 1 & 40 & $125: 1$ & 2.5 \\
S4 & BOFS & AMD & 1 & 40 & $125: 1$ & 2.5 \\
S5 & BOFS & AMD & 1 & 40 & $125: 1$ & 2.5 \\
\hline+ liquid & & & &
\end{tabular}

BOFS stability assessment - S1 system

To assess the stability of BOFS in relation to the availability of metals in the medium, the S1 system (BOFS/DEIONIZED WATER $\mathrm{pH} 2.5$ ) was monitored. Initially, $300 \mathrm{~mL}$ of deionized water with $\mathrm{pH}=$ 6.3 was separated. Then, approximately $15 \mu \mathrm{L}$ of $\mathrm{H}_{2} \mathrm{SO}_{4}\left(98 \%\right.$ and $\left.1.84 \mathrm{~g} . \mathrm{cm}^{3}\right)$ in $300 \mathrm{~mL}$ of water was added for S1, S3, S4, and S5 systems, resulting in an increase of $30 \mathrm{mg} . \mathrm{L}^{-1}$ of sulfate in these systems. After these adjustments, the EH $(0.67 \mathrm{mV})$ and electrical conductivity $\left(4,94 \mathrm{mS} . \mathrm{cm}^{-1}\right)$ of the AMD were measured.

Subsequently, $1 \mathrm{~g}$ of BOFS and $40 \mathrm{~mL}$ of this acidified deionized water solution were transferred to each of the seven Falcon tubes of the S1 system, reaching a ratio of 25:1 S/L. Flasks were subjected to agitation (150-160 rpm) in a thermostated shaker at a temperature of $\sim 25 \pm 2{ }^{\circ} \mathrm{C}$. Samples were collected at $0,6,24,48,144,240$, and $408 \mathrm{~h}$ for physical-chemical and arsenic and sulfate analyses. The T7 flask, corresponding to the experiment time (408 h) was also analyzed for $\mathrm{Ca}, \mathrm{Fe}, \mathrm{Mn}, \mathrm{Mg}$, and $\mathrm{Na}$ in ICP-OES. 
In this stage, three systems were analyzed: $\mathrm{S} 3$ (BOFS/AMD); $\mathrm{S} 4$ (BOFS/AMD/ $\mathrm{H}_{2} \mathrm{O}_{2} 0.5 \mathrm{mM}$ ); and $\mathrm{S} 5$ (BOFS/AMD/ $/ \mathrm{H}_{2} \mathrm{O}_{2} 1 \mathrm{mM}$ ) to which $5 \mathrm{~g}$ of BOFS in $40 \mathrm{~mL}$ of AMD was added in FalconTM tubes. This $\mathrm{S} / \mathrm{L}$ ratio of $125 \mathrm{~g}: 1 \mathrm{~L}$ of BOFS and AMD is similar to the $\mathrm{S} / \mathrm{L}$ ratios proposed in other studies (Jafaripour et al. 2015; Masindi et al, 2018; Name and Sheridan, 2014). For S4 and S5 systems, $\mathrm{H}_{2} \mathrm{O}_{2}$ ( $29 \% \mathrm{p} / \mathrm{p}$ ) was added to compare the efficiency with respect to the $\mathrm{S} 3$ system, which contained no oxidizing agent. Considering that BOFS contains $\sim 50 \%$ of ZVI in the $\mathrm{S} 4$ system, $10 \mu \mathrm{L} \mathrm{H}_{2} \mathrm{O}_{2}$ was added at a ratio of $1 \mathrm{~g}: 0.5 \mathrm{mM} \mathrm{ZVI} / \mathrm{H}_{2} \mathrm{O}_{2}$ (Guo et al. 2015, Guo et al. 2016). In the $\mathrm{S} 5$ system, $20 \mu \mathrm{L} \mathrm{H}_{2} \mathrm{O}_{2}$ was added to evaluate a ratio of $1 \mathrm{~g}: 1 \mathrm{mM} \mathrm{ZVI} / \mathrm{H}_{2} \mathrm{O}_{2}$. The peroxide volume was added above the BOFS sample in FalconTM tubes. The mixture was allowed to rest for $10 \mathrm{~min}$ to promote longer contact between $\mathrm{H}_{2} \mathrm{O}_{2}$ and the BOFS; then, $40 \mathrm{~mL}$ was added to AMD in all tubes.

In a $2 \mathrm{~L}$ beaker were added $1500 \mathrm{~mL}$ of AMD, $7.5 \mathrm{~mL}$ of As (V) stock solution $\left(1000 \mathrm{mg} \cdot \mathrm{L}^{-1}\right)$ of $\mathrm{As}(\mathrm{V})$ $\left(\mathrm{Na}_{2} \mathrm{HAsO}_{4} .7 \mathrm{H}_{2} \mathrm{O}\right)$ and $7.5 \mathrm{~mL}$ of As (III) $\left(\mathrm{NaAsO}_{2}\right)$. These reagents were added to enrich AMD with 10 $\mathrm{mg} \cdot \mathrm{L}^{-1}$ of total As $(\operatorname{As}(\mathrm{V})+\mathrm{As}(\mathrm{III}))$. Subsequently, this solution was transferred to the flasks of the $\mathrm{S} 3$, S4, and S5 systems.

The closed FalconTM tubes containing $5 \mathrm{~g}$ of BOFS and $40 \mathrm{~mL}$ of AMD remained under agitation (150$160 \mathrm{rpm}$ ) in a thermostated shaker at a temperature of $25 \pm 2{ }^{\circ} \mathrm{C}$. At $0,0.5,1,3,6,24,72,144,216,312$, 480 , and $648 \mathrm{~h}$, the tubes corresponding to each time were removed for physical-chemical analysis of arsenic and sulfate. The samples corresponding to the times T0, T2 (0.5 h), T4 (3 h), and T12 (648 h) were also analyzed for $\mathrm{Ca}, \mathrm{Fe}, \mathrm{Mn}, \mathrm{Mg}$, and $\mathrm{Na}$ using ICP-OES.

\subsection{Geochemical modeling}

Based on the results of the physical-chemical characterization of the BOF solid phases, geochemical modeling was performed before and after the experiments using the PHREEQC software (Parkhurst and Appelo 1999). With the modeling, the speciation of the ions in solution and their ion activities, the saturation indices of mineral phases, and the precipitations and physicochemical parameters of the solutions were obtained. The experiments were modeled based on the chemical composition of AMD and the solid phases observed in the BOF before and after the S3 and S5 experiments. The calculated contents of the solids were divided into 50 equal parts and added sequentially to AMD. In the model, the phases found in the BOF samples were inserted before and after the experiments. The modeling was performed in a closed system as well as in the experiments. 
A Quality assurance and quality control (QA/QC) program has been established and implemented to guarantee reliable results. For liquid samples, quality control involved carrying out experiments in triplicate and publishing the data as mean values with standard deviations (SD). Data with a percentage difference (SD) of $\leq 10 \%$ in triplicate or duplicate samples were considered acceptable. For solid samples, the quality was monitored using a certified reference material (NIST SRM 2710A; Montana II Soil) and the recovery with standard deviation $(\mathrm{SD}) \leq 15 \%$ was considered good. As an analytical quality control, "blanks" (analysis BLK) were inserted, which allowed for the measurement of values below the quantification limits $(\mathrm{QL})$ of the method. Lutetium $\left(1 \mathrm{mg} . \mathrm{L}^{-1}\right)$ was used as an internal standard element to monitor the effects of the matrix and the sensitivity deviations of the ICP-OES instrument.

\section{RESULTS AND DISCUSSION}

\subsection{Characterization of BOFS}

Results of the granulometric analysis of the 250-g sample of raw BOFS are presented based on the parameters for calculating the granulometric composition according to Wentworth (1922). Figure S1 shows the percentages of the passing and granulometric curves. The results of the granulometric analyses showed that $95 \%$ of the material was below $0.52 \mathrm{~mm}, 50 \%$ below $0.21 \mathrm{~mm}$, and $5 \%$ below $0.06 \mathrm{~mm}$, which are considered fine sand.

Table 2 shows the percentage chemical composition of the main metals present in the BOFS and the certified material (CANMET Till-3). BOFS is mainly composed of Fe (84\%), Ca (3\%), and $\mathrm{Si}(1 \%)$. The concentrations of sulfur and carbon in the sample were $0.003 \%$ and $0.645 \%$, respectively.

Table 2 - Major and minor elements present in BOFS and certified material

\begin{tabular}{|c|c|c|c|c|c|c|c|c|c|}
\hline \multicolumn{10}{|l|}{$\%(\mathrm{p} / \mathrm{p})$} \\
\hline Samples & $\mathrm{Al}$ & $\mathrm{Ca}$ & $\mathrm{Fe}$ & $\mathrm{Mg}$ & $\mathrm{Mn}$ & $\mathrm{Na}$ & $P$ & $\mathrm{Si}$ & $\mathrm{Ti}$ \\
\hline A1 & $<0.10$ & 2.67 & 85.45 & 0.57 & 0.51 & 0.22 & $<0.05$ & 0.90 & $<0.025$ \\
\hline $\mathrm{A} 2$ & $<0.10$ & 2.84 & 81.93 & 0.64 & 0.50 & 0.24 & $<0.05$ & 0.98 & $<0.025$ \\
\hline Average \pm SD & - & $\begin{array}{l}2,76 \pm \\
0,088\end{array}$ & $\begin{array}{c}83,71 \pm \\
1,762\end{array}$ & $\begin{array}{l}0,61 \pm \\
0,034\end{array}$ & $\begin{array}{l}0,51 \pm \\
0,002\end{array}$ & $\begin{array}{l}0,23 \pm \\
0,009\end{array}$ & $\mathrm{NA}^{(1)}$ & $\begin{array}{l}0,94 \pm \\
0,044\end{array}$ & - \\
\hline \multicolumn{10}{|c|}{ CANMET Till- 3} \\
\hline Measured & 7.33 & 1.43 & 3.09 & 1.08 & 0.04 & 2.53 & $<\mathrm{QL}^{(2)}$ & 32.54 & 0.30 \\
\hline Certified & 6.46 & 1.88 & 3.05 & 1.03 & 0.05 & 1.96 & 0.05 & 32.30 & 0.29 \\
\hline
\end{tabular}


$\begin{array}{llllllllll}\text { Recovery (\%) } & 114 & 76 & 101 & 104 & 70 & 129 & - & 101 & 102\end{array}$

(1) not analyzed (2) quantification limit

BOFS characterization tests indicated that, according to NBR10004 (ABNT 2004), the waste originating from the crude BOFS sample is classified as Class I (hazardous) as it presents a reactive corrosive characteristic ( $\mathrm{pH}$ 12.56). All other parameters analyzed showed adequate concentrations. The results are shown in the Supplementary Material.

Analysis of the diffraction lines revealed the presence of the following main constituent phases: calcite $\left(\mathrm{CaCO}_{3}\right)$, hematite $\left(\mathrm{Fe}_{2} \mathrm{O}_{3}\right)$, wustite $(\mathrm{FeO})$, iron $(\mathrm{Fe})$, and magnesium oxide $(\mathrm{MgO})$ (Fig. 1). Any other minor constituent phases are difficult to identify because of the complexity of the diffractograms and the low intensity of their diffraction lines. The main peaks of $\mathrm{CaCO}_{3}$ were $2 \theta: 36(\mathrm{~d}=3.04 \AA), 47(\mathrm{~d}=1.92$ $\AA)$, and $39(\mathrm{~d}=2.28 \AA)$; those of $\mathrm{Fe}^{0}$ were observed at 20: $45(\mathrm{~d}=2.02 \AA), 65(\mathrm{~d}=1.43 \AA)$, and $85(\mathrm{~d}=$ $1.17 \AA)$ and those of FeO were observed at $2 \theta: 42(\mathrm{~d}=2.15 \AA), 32(\mathrm{~d}=2.47 \AA)$, and $61(\mathrm{~d}=1.51 \AA)$.

\section{Fig. 1 - XRD patterns of raw BOFS}

These results were confirmed by the Mossbauer spectrum (Figure S2), which provides, among other things, information about the structural, electrical, and magnetic properties of a solid, in this case, for the ${ }^{57} \mathrm{Fe}$ isotope. According to Goldanskii and Herber (1968), nuclear hyperfine interactions are disturbances that occur in the energy levels of the nucleus due to nuclear interactions and electrical and magnetic fields in the vicinity of the nucleus. Thus, it is possible to obtain the isomeric displacement $(\delta ; \mathrm{mm} / \mathrm{s})$ the quadrupolar unfolding $(\Delta / \varepsilon ; \mathrm{mm} / \mathrm{s})$ and from them, the iron fraction corresponds to the relative area for each of the iron oxidation states (Table 3). Of the total iron in the sample, it was identified that $48 \%$ corresponded to metallic iron $\left(\mathrm{Fe}^{0}\right), 41 \%$ to wustite $(\mathrm{FeO})$, and $11 \%$ may be part of maghemite $\left(\gamma-\mathrm{Fe}_{2} \mathrm{O}_{3}\right)$ and ferrihydrite $\left(\mathrm{Fe}_{5} \mathrm{HO}_{8} \cdot 4 \mathrm{H}_{2} \mathrm{O}\right)$.

Table 3 - Hyperfine parameters of paramagnetic sites of Mossbauer spectra adjustments for raw BOFS samples. Complementary results are presented in Table S4

\begin{tabular}{ccccc}
\hline Sample & Oxidation state & $\begin{array}{c}\delta(\mathrm{mm} / \mathrm{s}) \pm \\
(0.05 \mathrm{~mm} / \mathrm{s})\end{array}$ & $\begin{array}{c}\Delta / \varepsilon(\mathrm{mm} / \mathrm{s}) \pm \\
(0.05 \mathrm{~mm} / \mathrm{s})\end{array}$ & $\begin{array}{c}\text { Relative area } \\
\pm(1 \%)\end{array}$ \\
\hline \multirow{2}{*}{ RAW BOFS } & $\mathrm{Fe}^{0}$ & 0.0 & 0.0 & 48 \\
& $\mathrm{Fe}^{2+}(\mathrm{FeO})$ & 1.06 & 0.83 & 41 \\
\hline
\end{tabular}



(BOFS/AMD/ $\mathrm{H}_{2} \mathrm{O}_{2} 1 \mathrm{mM}$ ) systems as well as the Mossbauer results for the raw BOFS sample are shown in Fig. 2. It is observed that the iron oxidation sequence has been extended, resulting in hematite formation: $\alpha-\mathrm{Fe}\left(\mathrm{Fe}^{0}\right) \rightarrow \mathrm{FeO}$ (wustite) $\rightarrow \gamma-\mathrm{Fe}_{2} \mathrm{O}_{3}$ (maghemite) $\rightarrow \alpha-\mathrm{Fe}_{2} \mathrm{O}_{3}$ (hematite).

Fig. 2 - Percentage of iron phases for raw BOFS, BOFS after reaction with AMD (S3), BOFS after reaction with AMD (S3), and BOFS after reaction with AMD/ $\mathrm{H}_{2} \mathrm{O}_{2} 1 \mathrm{mM}$ (S5) by Mossbauer

Comparing the results of the percentage of Fe phases (Fig. 2) between the solid samples obtained after the tests of the BOFS + AMD and BOFS $+\mathrm{AMD}+\mathrm{H}_{2} \mathrm{O}_{2}$ systems, it was observed that at the end of the experiment, both the $\alpha-\mathrm{Fe}_{2} \mathrm{O}_{3}$ fraction and the $\gamma-\mathrm{Fe}_{2} \mathrm{O}_{3}$ (hematite) fraction in the BOFS + AMD system were higher than those in the system containing $\mathrm{H}_{2} \mathrm{O}_{2}$. This finding indicates that there was continuous oxidation of elemental $\mathrm{Fe}$ in the system containing an oxidizing agent, maintaining it primarily in the form of iron oxide (wustite-FeO).

\subsection{Characterization of aqueous samples}

Both the deionized water used in the S1 system and the AMD used in S3, S4, and S5 systems had a pH of

6. To acidify them to a $\mathrm{pH} 2.5, \sim 50 \mu \mathrm{L} \mathrm{H}_{2} \mathrm{SO}_{4}\left(98 \%\right.$ and $\left.1.84 \mathrm{~g} . \mathrm{cm}^{3}\right)$ in $1000 \mathrm{~mL}$ was added to $\mathrm{S} 1, \mathrm{~S} 3$, adjustments, both the Eh and the conductivity were measured in AMD, obtaining the values of $0.67 \mathrm{mV}$ and $4.94 \mathrm{mS} . \mathrm{cm}^{-1}$ respectively. After the analysis of AMD by ICP-OES (Table 4), a low concentration of As was observed. AMD was, then, added with 10 mg.L ${ }^{-1}$ of As.

Table 4 - Chemical characterization of AMD (ICP-OES)

\begin{tabular}{lcccccccccc}
\hline Parameter & $\mathbf{A g}$ & $\mathbf{A l}$ & $\mathbf{A s}$ & $\mathbf{A u}$ & $\mathbf{C a}$ & $\mathbf{C d}$ & $\mathbf{C o}$ & $\mathbf{C r}$ & $\mathbf{C u}$ & $\mathbf{F e}$ \\
\hline $\begin{array}{l}\text { Conc. } \\
\text { (mg. } \mathbf{L}^{-1} \text { ) }\end{array}$ & $<0.25$ & $<2.5$ & $<1.0^{*}$ & $<0.25$ & 497.06 & $<0.1$ & $<0.1$ & $<0.1$ & $<0.1$ & 10.20 \\
\hline Parameter & $\mathrm{Mg}$ & $\mathrm{Mn}$ & $\mathrm{Na}$ & $\mathrm{Ni}$ & $\mathrm{Pb}$ & $\mathrm{S}$ & $\mathrm{Sb}$ & $\mathrm{Sn}$ & $\mathrm{Ti}$ & $\mathrm{Zn}$ \\
\hline $\begin{array}{l}\text { Conc. } \\
\text { (mg. } \mathbf{L}^{-1} \text { ) }\end{array}$ & 755.92 & 5.49 & 68.34 & $<0.1$ & $<0.25$ & 1586.55 & $<0.1$ & $<0.25$ & $<0.25$ & $<1.0$ \\
\hline
\end{tabular}


The graphs in Fig. 3 show that the initial pH (2.5) of the S1 system (BOFS/DEIONIZED WATER pH

Fig. 3 - Variations of pH, Eh, conductivity, and Total Arsenic (As T) in the S1 system (BOFS/DEIONIZED WATER $\mathrm{pH}$ 2.5)

The increase in $\mathrm{pH}$ was due to the calcium carbonate contained in BOFS. The process of neutralizing an acidic solution by dissolving $\mathrm{CaCO}_{3}$ is quick and can be described by Eq. 5 at low pH values and by Eq. 6 with higher $\mathrm{pH}$ values (Blowes et al. 2003). Under alkaline conditions at a $\mathrm{pH}$ of $\sim 10$, the reaction shown in Eq. 7 prevails.

$$
\begin{aligned}
& \mathrm{CaCO}_{3(\mathrm{~s})}+2 \mathrm{H}^{+}{ }_{(\mathrm{aq})} \rightarrow \mathrm{Ca}^{2+}{ }_{(\mathrm{aq})}+\mathrm{H}_{2} \mathrm{CO}_{3(\mathrm{aq})} \\
& \mathrm{CaCO}_{3(\mathrm{~s})}+\mathrm{H}^{+}{ }_{(\mathrm{aq})} \rightarrow \mathrm{Ca}^{2+}{ }_{(\mathrm{aq})}+\mathrm{HCO}_{3(\mathrm{aq})}^{-} \\
& \mathrm{CaCO}_{3(\mathrm{~s})} \rightarrow \mathrm{Ca}^{2+}{ }_{(\mathrm{aq})}+\mathrm{CO}_{3^{2-}}{ }_{(\mathrm{aq})}
\end{aligned}
$$

It was observed that at the beginning of the experiment the redox potential (Eh) started at $\sim 800 \mathrm{mV}$ and during the first $6 \mathrm{~h}$, it decreased to $\sim 400 \mathrm{mV}$ and remained stable until the end of the experiment. This behavior is expected because the consumption of protons, through the mechanism presented in Eq. 5 and Eq. 6, causes the $\mathrm{pH}$ to increase and the Eh value to decrease. Considering the atmospheric pressure of 1 atm, the increase in $\mathrm{pH}$ and consequent decrease in Eh is consistent with the Nernst equation: $\mathrm{E}_{\mathrm{H}}=$ $-0.0591 \mathrm{pH}$. The low conductivity $(750 \mu \mathrm{S})$ of the $\mathrm{S} 1$ system confirms the low presence of ions in the solution at the end of the experiment (T $408 \mathrm{~h}$ ). Among the parameters analyzed (Ca, $\mathrm{Fe}, \mathrm{Mg}$, and $\mathrm{Mn}$ ), only $\mathrm{Ca}(10 \% \mathrm{p} / \mathrm{v})$ was solubilized into the medium, with a concentration of $78.1 \mathrm{mg} \cdot \mathrm{L}^{-1}$. Fe, $\mathrm{Mg}(1.25$ $\left.\mathrm{mg} . \mathrm{L}^{-1}\right)$, and $\mathrm{Mn}\left(0.05 \mathrm{mg} . \mathrm{L}^{-1}\right)$ were below the QL (quantification limit) at the end of the experiment. Sulfate was also below the QL throughout the monitoring period. Fig. 4 shows the Mössbauer analyses for raw BOFS and BOFS/DEIONIZED WATER pH 2.5 (S1 system). These analyses confirm the 
oxidation of the Fe phases: $\mathrm{Fe}^{0}$ and $\mathrm{Fe}^{2+}$ (magnetite) clearly showed an increase in the $\mathrm{Fe}^{3+}$ (hematite) phase.

Fig. 4 - Percentage of the iron phases for raw BOFS and BOFS / DEIONIZED WATER pH 2.5 of the S1 system after $408 \mathrm{~h}$

Evaluation of metal removal efficiency from AMD with oxidizing agent in $S 3, S 4$, and $S 5$ systems

The graphs of the physical-chemical parameter results (Fig. 5), demonstrate a similar behavior among S3 (BOFS/AMD), $\mathrm{S} 4$ (BOFS/AMD/ $\mathrm{H}_{2} \mathrm{O}_{2} 0.5 \mathrm{mM}$ ), and $\mathrm{S} 5$ (BOFS/AMD/ $\mathrm{H}_{2} \mathrm{O}_{2} 1 \mathrm{mM}$ ) in relation to $\mathrm{pH}, \mathrm{Eh}$, and conductivity parameters, mainly in S4 and S5 systems, which differ only in the concentration of peroxide used.

Fig. 5 - Variations in pH, Eh, conductivity, As, and sulfate in the samples of S3, S4, and S5 systems In view of the physicochemical results of $\mathrm{pH}$ and $\mathrm{Eh}$, it was observed that the systems simultaneously achieved balance after $0.5 \mathrm{~h}$, with a slight variation in the final $\mathrm{pH}$ and Eh of the $\mathrm{S} 3$ system compared to the others. The electrical conductivity (CE) remained constant from 0.5 . to $72 \mathrm{~h}$, decreasing until all systems reached a value of $\sim 2 \mathrm{mS} . \mathrm{cm}^{-1}$ in $648 \mathrm{~h}$. The removal of As in the S3, S4, and S5 systems was $95 \%$, resulting in the final concentration $<\mathrm{QL}\left(0.5 \mathrm{mg} \cdot \mathrm{mg} \cdot \mathrm{L}^{-1}\right)$, and the removal of sulfate was $60 \%-$ $70 \%$ (final concentration $=1400-1900 \mathrm{mg} . \mathrm{L}^{-1}$ ), resulting in a higher concentration than the maximum value allowed by Brazilian legislation in surface waters $\left(250 \mathrm{mg} . \mathrm{L}^{-1}\right)$.

Regarding the removal percentage, there were no significant differences among S3 (BOFS/AMD), S4 (BOFS/AMD/ $\mathrm{H}_{2} \mathrm{O}_{2} 0.5 \mathrm{mM}$ ), and $\mathrm{S} 5\left(\mathrm{BOFS} / \mathrm{AMD} / \mathrm{H}_{2} \mathrm{O}_{2} 1 \mathrm{mM}\right.$ ) systems, as shown in Fig. 6. Considering the lack of significant difference in the kinetics of S4 and S5 systems, for which only the $\mathrm{H}_{2} \mathrm{O}_{2}$ concentration differs, the removal of other metals $(\mathrm{Ca}, \mathrm{Fe}, \mathrm{Mg}$, and $\mathrm{Mn})$ was evaluated at the following time intervals: T0; T1 (0.5 h), T3 (3 h), and T12 (648 h). 
It is observed that, on average, $700 \mathrm{mg} . \mathrm{L}-1$ of Ca remained in the S3 and S5 systems. In relation to Fe, after 3 hours of experiment, all quantifiable Fe precipitated in both the S3 and S5 systems. This proved that the presence of $\mathrm{H}_{2} \mathrm{O}_{2}$ in the $\mathrm{S} 5$ system delayed the precipitation of $\mathrm{Fe}$, but did not make the system more efficient in removing contaminants. In the S3 system, the concentration of soluble iron was considerably low since the beginning of the experiment. In the $\mathrm{S} 5$ system, as the $\mathrm{pH}$ of the solution remained low until $0.5 \mathrm{~h}$, precipitation of the sulfate in the form of ferric sulfate and of ferrous sulfate may have occurred.

Studies carried out by Pantuzzo et al. (2008) proved that the As precipitation or sorption mechanism in the form of amorphous ferric arsenate $(\mathrm{FeAsO} 4.2 \mathrm{H} 2 \mathrm{O})$, with the same molecular formula as the escorodite, is unfavorable in alkaline conditions, being favored in the $\mathrm{pH}$ range 1.5-4.0. Laboratory experiments conducted by Langmuir et al. (2006) using a solution rich in arsenic from uranium mining yielded the same results. In these experiments, the solution was neutralized from $\mathrm{pH} 2$ to $\mathrm{pH} 8$ with the addition of $\mathrm{Ca}(\mathrm{OH})_{2}$. A small amount of crystalline scorodite $\left(\mathrm{K}_{\mathrm{ps}}=10^{-25,83} \mathrm{~mol} . \mathrm{L}^{-1}\right)$ precipitated at a $\mathrm{pH}$ close to 2 and amorphous iron arsenate $\left(\mathrm{K}_{\mathrm{ps}}=10^{-23} \mathrm{~mol} \cdot \mathrm{L}^{-1}\right)$ precipitated at a $\mathrm{pH}$ between 2 and 3 . The removal of arsenic during neutralization can be explained by assuming precipitation of $90 \%-98 \%$ of As $(\mathrm{V})$ as escorodite when $\mathrm{pH}=2-3$; the adsorption of the remaining As $(\mathrm{V})$ by a precipitate as amorphous iron arsenate occurs between a $\mathrm{pH}$ of 2.18 and 7.37. Although the As (V) removal mechanism remains unknown, our results indicate that it is irreversible. This $\mathrm{pH}$ acid condition is maintained for a short time in the studied systems, considering that within $30 \mathrm{~min}$ the $\mathrm{pH}$ becomes $\sim 12$. Considering the $\mathrm{pH}$ and $\mathrm{EH}$ conditions that formed in the system (high $\mathrm{pH}$ and oxidizing environment) and the solubility product of ferric arsenate $\left(\mathrm{Kps}=10^{-24} \mathrm{~mol} \cdot \mathrm{L}^{-1}\right)$ and calcium arsenate $\left(\mathrm{Kps}=10^{-19} \mathrm{~mol} . \mathrm{L}^{-1}\right)$, the thermodynamic conditions in the system favor species stability. The behaviors of $\mathrm{Mg}$ and $\mathrm{Mn}$ in both systems were similar, and at the end of the experiment, the concentration of soluble species reached values lower than the QL of the method.

\subsection{Geochemical modeling}



PHREEQC_ThermoddemV1.10_06Jun2017.dat (Blanc et al. 2012). The BOFS mass used in the experiments $(5 \mathrm{~g})$ was divided into 50 equal fractions $(0.1 \mathrm{~g}$ each $)$ and these fractions were added gradually to $40 \mathrm{~mL}$ of the solutions in experiments $\mathrm{S} 3$ (BOFS) and $\mathrm{S} 5$ (BOFS $+\mathrm{H}_{2} \mathrm{O}_{2}$ ) (see Materials and Methods for further details). Under these conditions, the geochemical modeling reproduced the physicalchemical conditions (Fig. 7-A) and obtained the same experimental results observed at 648th $\mathrm{h}$ of incubation. From the 20 th addition of the $2 \mathrm{~g}$ of BOFS in both models (Fig. 7-B), the ion concentrations in solution $\left(\mathrm{Ca}^{2+}, \mathrm{SO}_{4}^{2-}, \mathrm{Mn}^{2+}, \mathrm{As}^{3+}\right.$, and $\left.\mathrm{As}^{5+}\right)$ and the precipitations of crystalline and amorphous compounds were observed in the experiments (Fig. 7-C). This means that only $2 \mathrm{~g}$ of the BOFS reacted in both experiments; however, in the modeling, other results would be achieved if the system reached chemical equilibrium, especially in relation to $\mathrm{pH}$, which is a little higher in the modeling.

Fig. 7-A shows the reduction in $\mathrm{EH}$, which can be explained by the oxidation of $\mathrm{Fe}^{0}$ (releasing electrons into the system) and $\mathrm{FeO}$ together with the formation of $\mathrm{Fe}_{2} \mathrm{O}_{3}$ (hematite) and $\mathrm{Mn}^{2+} \mathrm{Fe}_{2}{ }^{3+} \mathrm{O}_{4}$ (jacobsite) (Fig. 7-C). Gypsum $\left(\mathrm{CaSO}_{4} \cdot 2 \mathrm{H}_{2} \mathrm{O}\right)$ precipitation occurred since the beginning of the addition of BOFS in the solutions. Before the addition of BOFS, the gypsum saturation index in the AMD (saturation index $(S I)=0.03)$ indicated that the DAM was initially in equilibrium with gypsum. The solubilization of calcite, present in the BOFS added to the system, provided the $\mathrm{Ca}^{2+}$ necessary for the precipitation of sulfate in the form of gypsum. With the $\mathrm{pH}$ stabilized at $\sim 10$ after the addition of $0.3 \mathrm{~g}$ of BOFS, brucite $\left(\mathrm{Mg}(\mathrm{OH})_{2}\right)$ precipitation began (Fig. 7-C). The $\mathrm{pH}$ was stabilized around 10 until the addition of $2 \mathrm{~g}$ of BOF. The precipitation of $\mathrm{Ca}_{5}\left(\mathrm{AsO}_{4}\right)_{3} \mathrm{OH}$, which started with the addition of $1.5 \mathrm{~g}$ of $\mathrm{BOF}$, must have been controlled by competition with the gypsum for $\mathrm{Ca}^{2+}$ available in solution. With the gypsum precipitation since the beginning of the experiment, there was a decrease in the sulfate available for gypsum formation, thereby facilitating the precipitation of $\mathrm{Ca}_{5}\left(\mathrm{AsO}_{4}\right)_{3} \mathrm{OH}$. After the precipitation of $\mathrm{Ca}_{5}\left(\mathrm{AsO}_{4}\right)_{3} \mathrm{OH}$, the concentration of dissolved $\mathrm{Ca}^{2+}$ remained constant in the solution; there was no further dissolution of the added calcite until BOFS addition was complete. Thus, from the beginning of the experiment, the precipitation of gypsum inhibited the removal of As until the $\mathrm{SO}_{4}{ }^{2-}$ in the solution was consumed and the saturation/precipitation of the gypsum was reduced.

The solubility of $\mathrm{Mg}$ was controlled by the precipitation of brucite, which removed $\mathrm{Mg}$ almost entirely. With the termination of brucite and $\mathrm{Ca}_{5}\left(\mathrm{AsO}_{4}\right)_{3} \mathrm{OH}$ precipitations (Fig. 7-C) after the addition of $2 \mathrm{~g}$ of 
with the continued addition of BOFS up to $5 \mathrm{~g}$ (Fig. 7-A). Mn was removed after the addition of $1.75 \mathrm{~g}$ of BOFS (Fig. 7-A) as a result of jacobsite $\left(\mathrm{Mn}^{2+} \mathrm{Fe}_{2}{ }^{3+} \mathrm{O}_{4}\right)$ precipitation in $\mathrm{S} 3$ and $\mathrm{S} 5$ systems, under stable $\mathrm{pH}$ and Eh conditions (Figs. 7-B and 7-C).

This suggests that the precipitation of jacobsite was controlled by the availability of $\mathrm{Fe}^{2+}$ in solution. This was the only phase containing Mn identified in the modeling capable of removing Mn from the solution in experiments S3 and S5. In modeling, the reduction in Eh is ascribed to the continued oxidation of the Fe phases.

Fig. 7 - Graphical representation of the conditions proposed in the modeling by PHREEQC using PHREEQC_ThermoddemV1.10_06Jun2017.dat database (Blanc et al. 2012)

The mineralogical composition of the XRD patterns of (A) raw BOFS, (B) BOFS/AMD, and (C) BOFS/AMD/ $\mathrm{H}_{2} \mathrm{O}_{2} 1 \mathrm{mM}$ are shown in Fig. 8, confirming the species observed in geochemical modeling. The main peaks of $\mathrm{CaSO}_{4} .2 \mathrm{H}_{2} \mathrm{O}$ were $2 \theta: 11.67(\mathrm{~d}=7.57 \AA)$ and $20.8(\mathrm{~d}=4.27 \AA)$. For $\mathrm{Ca}_{5}\left(\mathrm{AsO}_{4}\right)_{3} \mathrm{OH}$ (johnbaumite), the peaks were observed at 29: $31(\mathrm{~d}=2.86 \AA)$ and $32(\mathrm{~d}=2.78 \AA)$ (Bothe and Brown 1999, Zhu et al. 2006).

Fig. 8 - XRD patterns of (A) raw BOFS , (B) BOFS/AMD, and (C) BOFS/AMD/ $\mathrm{H}_{2} \mathrm{O}_{2} 1 \mathrm{mM}$ The majority of elements present in the S1 system (BOFS/AMD) were also detected by SEM with EDS (Fig. 9). Figure S3 show the morphological properties of BOFS and BOFS after contact with AMD and $\mathrm{H}_{2} \mathrm{O}_{2}$ obtained by SEM image corresponding chemical mappings by EDS. It was observed that the slag resulting from the S3 system (BOFS/AMD) has a leaf and rod-shaped structures. S5 system particles contained spherical aggregates of irregular shapes with coral reef-like structures. The surface of these forms is smooth, representing a typical crystalline form of gypsum $\left(\mathrm{CaSO}_{4}\right)$. Similar results were reported by $\mathrm{Du}$ et al. (2016). The resulting residue was compact, indicating that the material formed was crystalline. The spherical structures indicate the iron particles and the aggregates of small particles of varying sizes and shapes, such as stems, leaves, reefs, and bulky nodules, indicating the formation of new precipitates (Masindi et al. 2017). 
Fig. 9 -SEM image of (A) BOFS (2000x) and (B) BOFS (20000x). Highlighted area indicates where EDS was analyzed. (C, D, E, F) Corresponding chemical mappings obtained by EDS

This study showed that a BOFS can be an economical alternative to treat acid mine drainage with high arsenic and sulfate. The precipitation of arsenic in the form of calcium arsenate $\left(\mathrm{Ca}_{5}\left(\mathrm{AsO}_{4}\right)_{3} \mathrm{OH}\right)$ and having a low solubility constant $\left(\mathrm{Ksp}=6.8 \times 10^{-19} \mathrm{~mol} \cdot \mathrm{L}^{-1}\right)$, suggests the stability of this compound, thus simplifying the disposal of this compound. residue after use.

Despite being rich in metallic iron (ZVI) and iron oxyhydroxides, as shown in the characterization by XRD, SEM and Mossbauer, the experiments and geochemical modeling in PHREEQC proved that iron compounds were not the main source of removal of contaminants. The use of the oxidizing agent $\left(\mathrm{H}_{2} \mathrm{O}_{2}\right)$ and BOFS to favor the formation of iron oxy-hydroxides did not exceed the removal rate achieved by the system that contained only BOFS. The concentration of calcium carbonate $\left(\mathrm{CaCO}_{3}\right)$ was sufficient to raise the $\mathrm{pH}$ from 2.5 to $\mathrm{pH} 10$ and remove $100 \%$ As and $70 \%$ sulfate. In addition to these contaminants, there was also total removal of $\mathrm{Mg}, \mathrm{Mn}$, and Fe. This study also found that BOFS has the potential to neutralize AMD's acidity and mitigate the toxic effects of these chemical compounds.

A disadvantage of this proposal is that the remaining sulfate concentration is still high and, in the case of disposal of this effluent directly into a watercourse, it may compromise the quality of the water intended for human consumption, whose limit is $250 \mathrm{mg} . \mathrm{L}^{-1}$ of sulfate. This means that a technology for polishing this effluent must be associated with the process.

\section{DECLARATIONS}

Ethics approval and consent to participate: No applicable available from the corresponding author on reasonable request. 
Funding: This work was supported by the Foundation of Support and Research of the state of Minas Gerais (FAPEMIG), the Coordination of Superior Level Staff Improvement (CAPES) and the National Council for Scientific and Technological Development (CNPq). The funding sources were not involved in study design, nor the collection, analysis, and interpretation of data, nor in the writing of the report, nor in the decision to submit the article for publication.

Authors' contributions: study conception and design - S. F. Araujo, V. S.T. Ciminelli and C. L. Caldeira; assays execution - S. F. Araujo and J. P. Rodrigues; analysis - S. F. Araujo, J. P. Rodrigues; V. S.T. Ciminelli and C. L. Caldeira; results interpretation and writing - S. F. Araujo, V. S.T. Ciminelli, C. L. Caldeira, G. F. Simões and R. P. Borba. All authors contributed to interpretation of results and manuscript revision. All authors read and approved the final manuscript.

\section{REFERENCES}

ABNT (2004) Associação Brasileira de Normas Técnicas, Resíduos sólidos - Classificação, Rio de Janeiro, pp. 71

Anderson PR, Benjamin MM (1985) Effect of silicon on the crystallization and adsorption properties of ferric oxides. Environmental Science \& Technology 19, 1048-1053

Araujo SF, Caldeira CL, Ciminelli VST, Silva A, Amorim CC (2019) Versatility of iron-rich steel waste for the removal of high arsenic and sulfate concentrations in water. Environmental Science \& Pollution Research International 26, 4266-4276

Blanc P, Lassin A, Piantone P, Azaroual M, Jacquemet N, Fabbri A, Gaucher EC (2012) Thermoddem: A geochemical database focused on low temperature water/rock interactions and waste materials. Applied Geochemistry 27, 2107-2116

Bothe JV, Brown PW (1999) Arsenic immobilization by calcium arsenate formation. Environmental Science \& Technology 33, 3806-3811

Du Y, Lu Q, Chen H, Du Y, Du D (2016) A novel strategy for arsenic removal from dirty acid wastewater via $\mathrm{CaCO}_{3}-\mathrm{Ca}(\mathrm{OH})_{2}-\mathrm{Fe}(\mathrm{III})$ processing. Journal of Water Process Engineering 12, 41-46

Guan X, Sun Y, Qin H, Li J, Lo IM, He D, Dong H (2015) The limitations of applying zero-valent iron technology in contaminants sequestration and the corresponding countermeasures: The development in zero-valent iron technology in the last two decades (1994-2014). Water Research $75,224-248$

Guo H, Stüben D, Berner Z, Kramar U (2008) Adsorption of arsenic species from water using activated siderite-hematite column filters. Journal of Hazardous Materials 151, 628-635

Guo X, Yang Z, Liu H, Lv X, Tu Q, Ren Q, Xia X, Jing C (2015) Common oxidants activate the reactivity of zero-valent iron (ZVI) and hence remarkably enhance nitrate reduction from water. Separation \& Purification Technology 146, 227-234

Guo X, Yang Z, Dong H, Guan X, Ren Q, Lv X, Jin X (2016) Simple combination of oxidants with zerovalent-iron (ZVI) achieved very rapid and highly efficient removal of heavy metals from water. Water Research 88, 671-680

Goldanskii V.I, Herber R.H (1968) Chemical Applications of Mössbauer Spectroscopy. Academic Press, New York.

Jafaripour A, Rowson NA, Ghataora GS (2015) Utilisation of residue gas sludge (BOS sludge) for removal of heavy metals from acid mine drainage (AMD). International Journal of Mineral Processing 144, 90-96

Kefeni KK, Msagati TAM, Mamba BB (2017) Acid mine drainage: Prevention, treatment options, and resource recovery: A review. Journal of Cleaner Production 151, 475-493

Langmuir D (1971) Eh-pH determination, Sedimentary petrology. John Wiley \& Sons, New York 
Langmuir D, Mahoney J, Rowson J (2006) Solubility products of amorphous ferric arsenate and crystalline scorodite (FeAsO4-2H2O) and their application to arsenic behavior in buried mine tailings, Geochimica et Cosmochimica Acta, Volume 70, Issue 12

Li Y, Guo X, Dong H, Luo X, Guan X, Zhang X, Xia X (2018) Selenite removal from groundwater by zero-valent iron (ZVI) in combination with oxidants. Chemical Engineering Journal 345, 432440

Masindi V, Akinwekomi V, Maree JP, Muedi KL (2017) Comparison of mine water neutralisation efficiencies of different alkaline generating agents. Journal of Environmental Chemical Engineering 5, 3903-3913

Masindi V, Osman MS, Mbhele RN, Rikhotso R (2018) Fate of pollutants post treatment of acid mine drainage with basic oxygen furnace slag: Validation of experimental results with a geochemical model. Journal of Cleaner Production 172, 2899-2909

Mayes WM, Batty LC, Younger PL, Jarvis AP, Kõiv M, Vohla C, Mander U (2009) Wetland treatment at extremes of pH: A review. Science of the Total Environment 407, 3944-3957

Name T, Sheridan C (2014). Minerals Engineering 64, 15-22

Pantuzzo FL, Ciminelli VST, Brito W (2008) New evidences for the role of precipitation and adsorption during Fe(III)-As(V) coprecipitation. Hydrometallurgy: Proceedings of the Sixth International Symposium 10p

Parkhurst DL, Appelo CAJ (1999) Users guide to Phreeqc (Version 2) -: A computer program for speciation, batch-reactions, one-dimensional transport and inverse geochemical calculations. Water Resources 4259, 99

Satapanajaru T, Shea PJ, Comfort SD, Roh Y (2003) Green rust and iron oxide formation influences metolachlor dechlorination during zerovalent iron treatment. Environmental Science \& Technology 37, 5219-5227

Skousen JG, Sexstone A, Ziemkiewicz PF (2000) Acid mine drainage control and treatment. Agronomy Monographs 41, 131-168

Skousen J, Zipper CE, Rose A, Ziemkiewicz PF, Nairn R, McDonald LM, Kleinmann RL (2017) Review of passive systems for acid mine drainage treatment. Mine Water \& the Environment 36, 133 153

Tolonen ET, Sarpola A, Hu T, Rämö J, Lassi U (2014) Acid mine drainage treatment using by-products from quicklime manufacturing as neutralization chemicals. Chemosphere 117, 419-424

Blowes DW, Ptacek CJ, Jambor JL, Weisener CG (2003) The geochemistry of acid mine drainage 9, 149. 204

Wentworth CK (1922) A scale of grade and class terms for clastic sediments. The Journal of Geology 30, 377-392

Yang Z, Shan C, Zhang W, Jiang Z, Guan X, Pan B (2016) Temporospatial evolution and removal mechanisms of $\mathrm{As}(\mathrm{V})$ and $\mathrm{Se}(\mathrm{VI})$ in $\mathrm{ZVI}$ column with $\mathrm{H} 2 \mathrm{O} 2$ as corrosion accelerator. Water Research 106, 461-469

Zhu YN, Zhang XH, Xie QL, Wang DQ, Cheng GW (2006) Solubility and stability of calcium arsenates at $25^{\circ} \mathrm{C}$. Water, Air, \& Soil Pollution 169, 221-238 
Figures

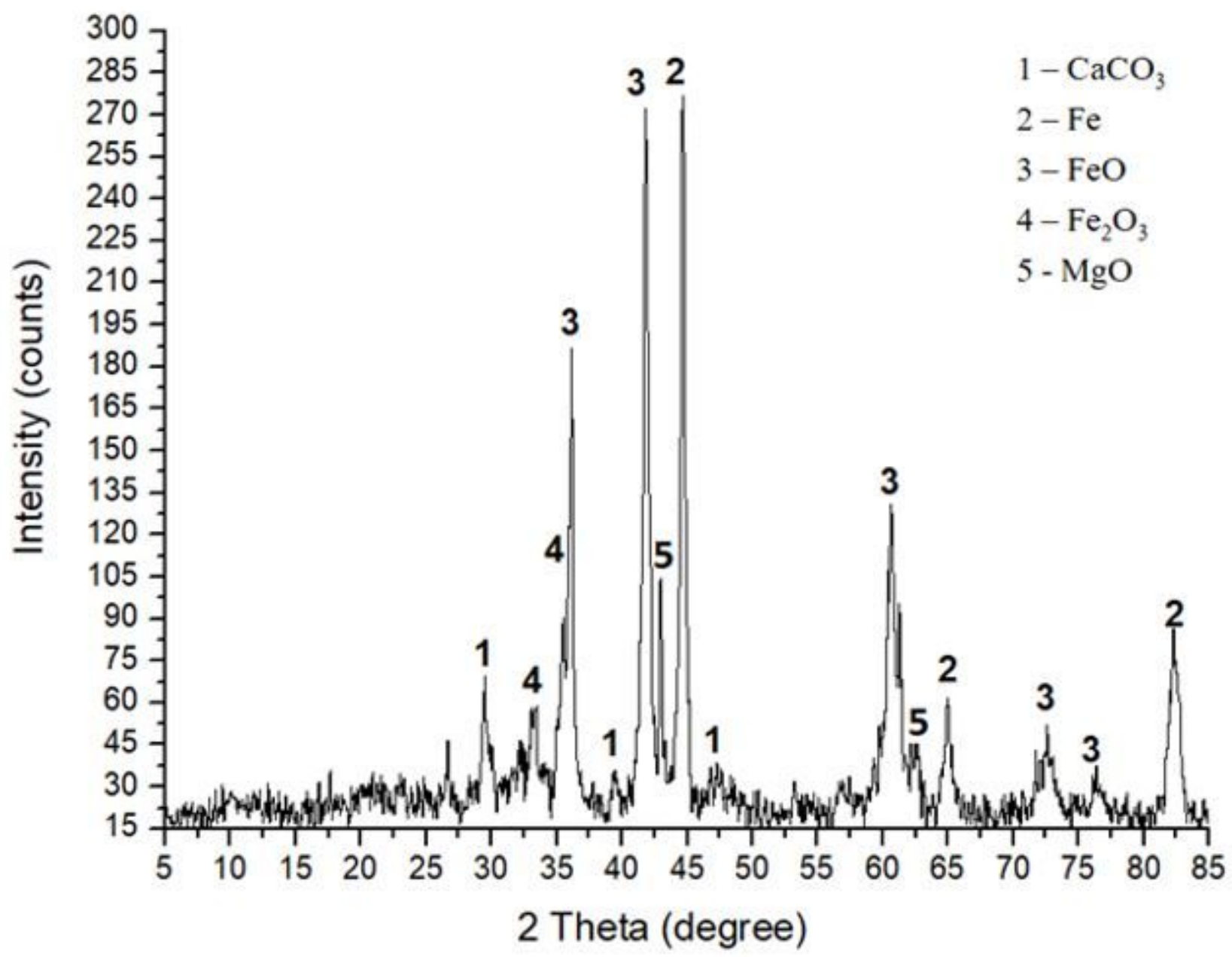

Figure 1

XRD patterns of raw BOFS. 


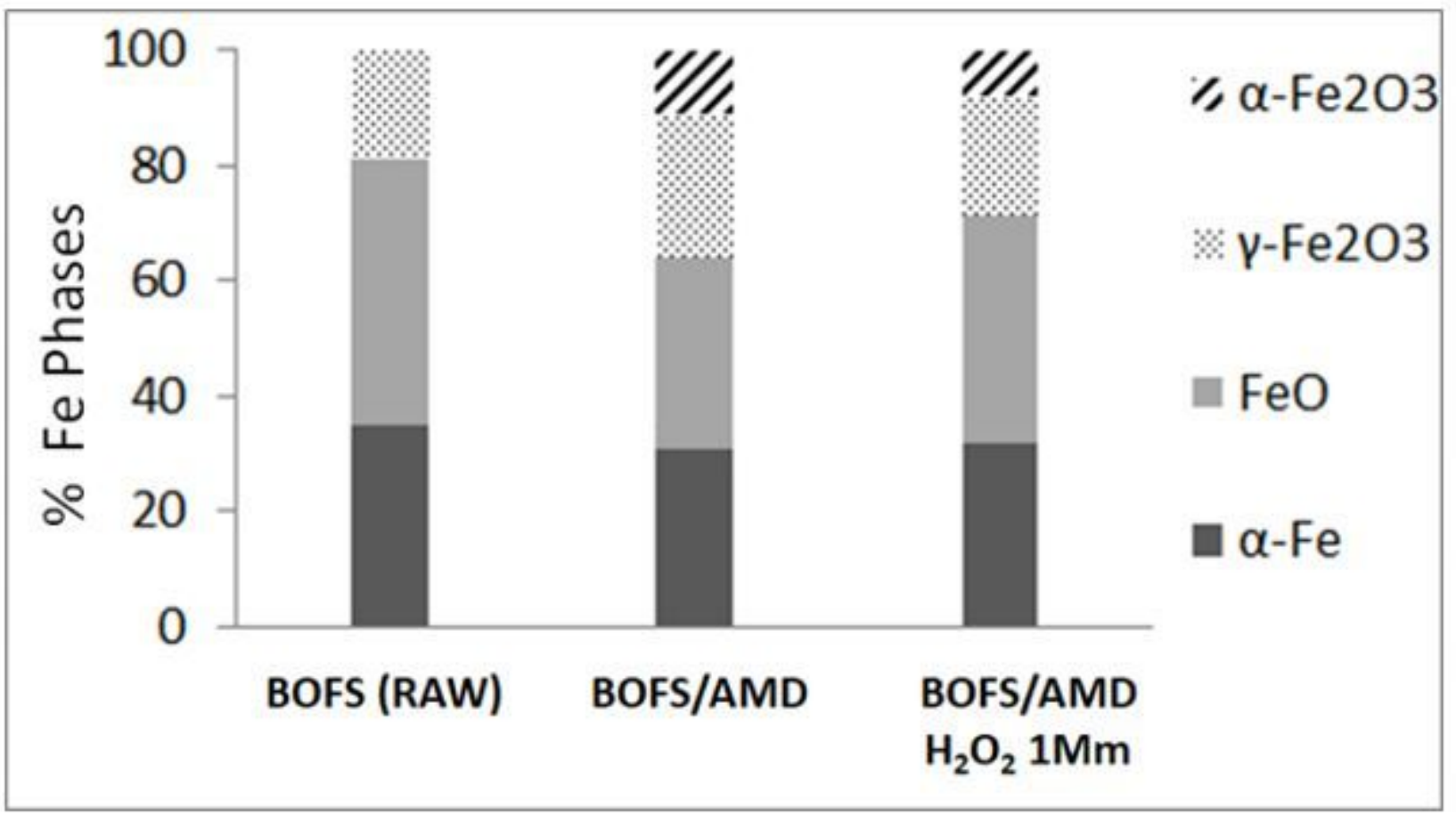

Figure 2

Percentage of iron phases for raw BOFS, BOFS after reaction with AMD (S3), BOFS after reaction with AMD (S3), and BOFS after reaction with AMD/H2O2 $1 \mathrm{mM}$ (S5) by Mossbauer.
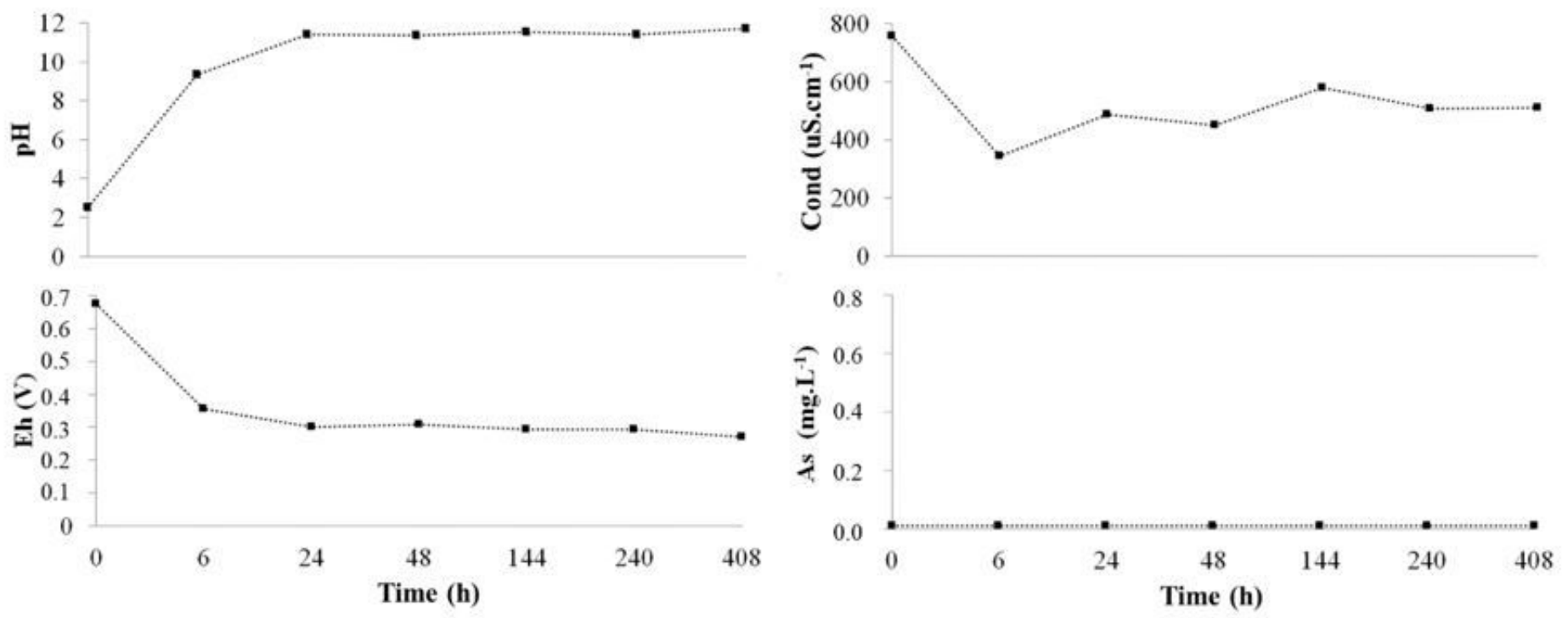

Figure 3

Variations of $\mathrm{pH}$, Eh, conductivity, and Total Arsenic (As T) in the $\mathrm{S} 1$ system (BOFS/DEIONIZED WATER $\mathrm{pH} 2.5)$. 


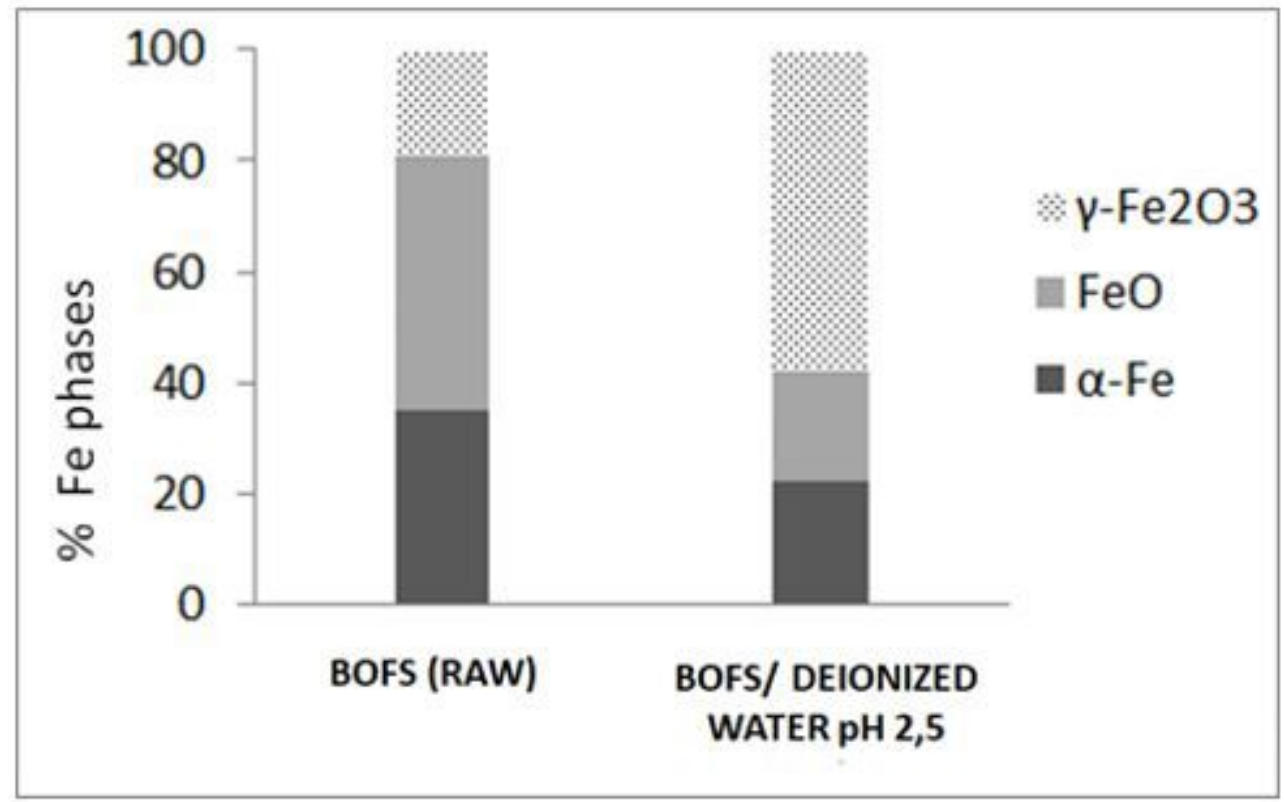

Figure 4

Percentage of the iron phases for raw BOFS and BOFS / DEIONIZED WATER pH 2.5 of the S1 system after $408 \mathrm{~h}$. 

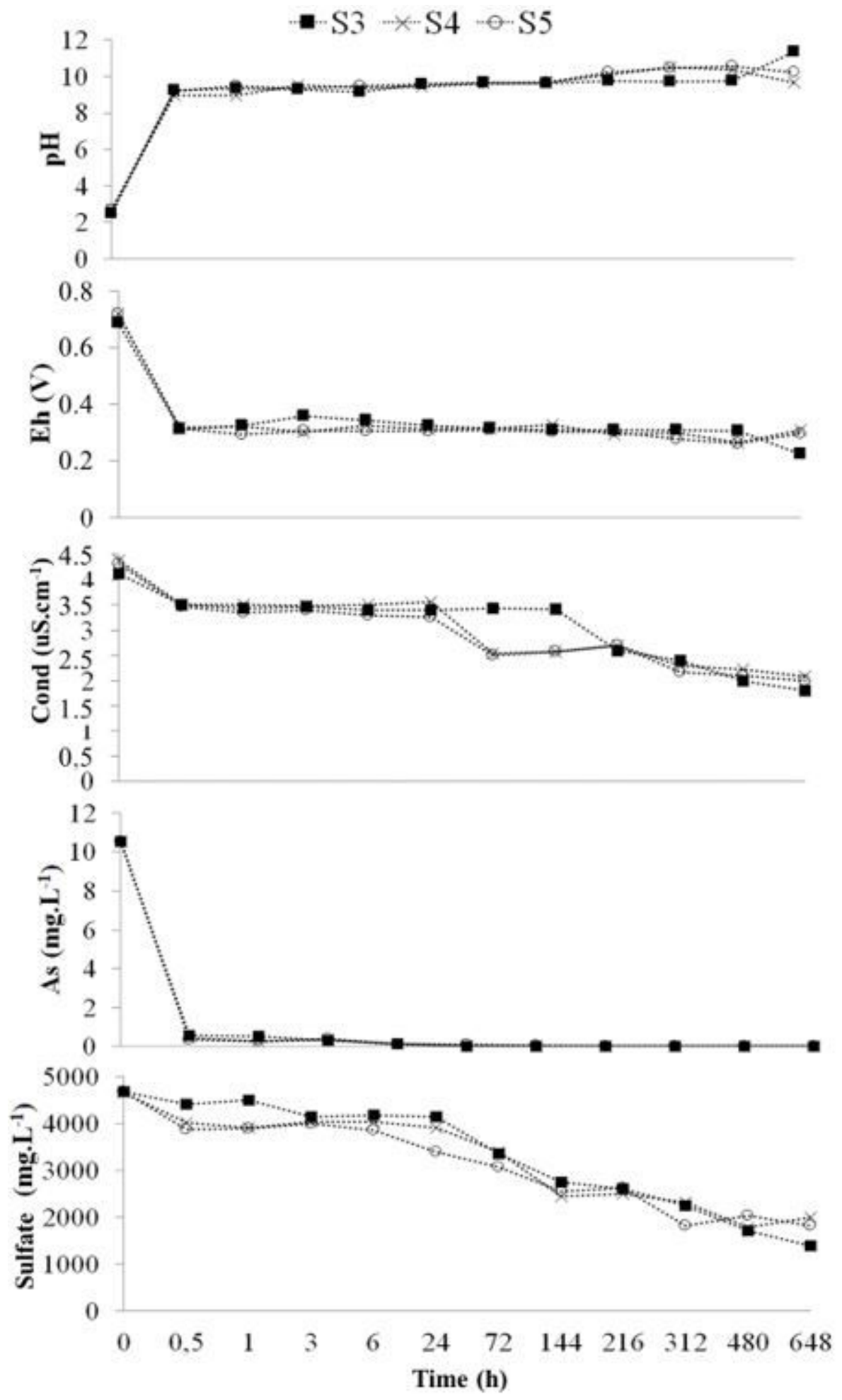

\section{Figure 5}

Variations in pH, Eh, conductivity, As, and sulfate in the samples of S3, S4, and S5 systems. 


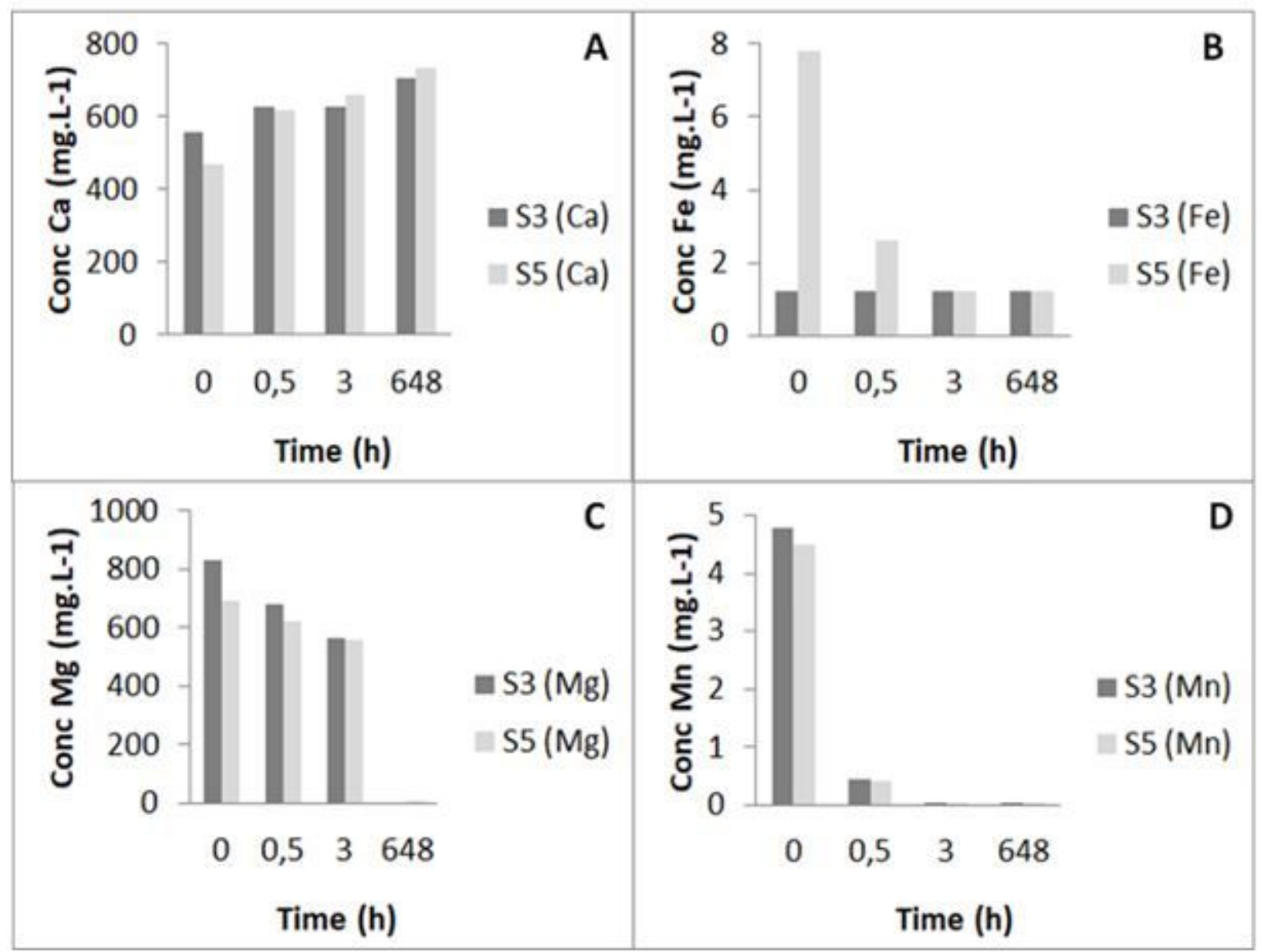

Figure 6

Concentration (mg.L-1) of $\mathrm{Ca}(\mathrm{A}), \mathrm{Fe}(\mathrm{B}), \mathrm{Mg}(\mathrm{C})$, and $\mathrm{Mn}(\mathrm{D})$ in S3 and S5 systems. 


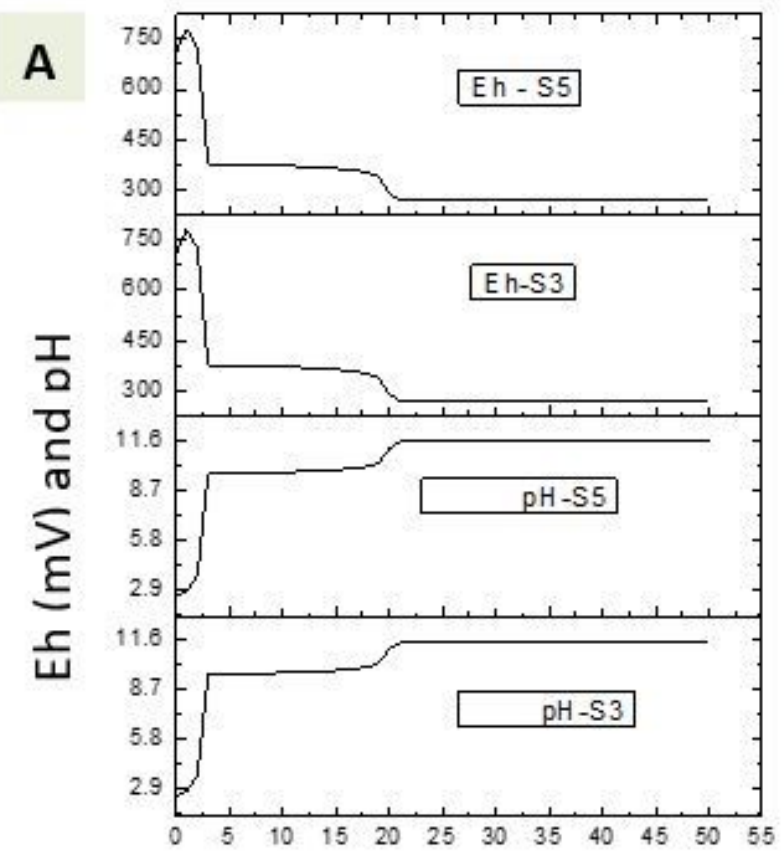

Number of additions

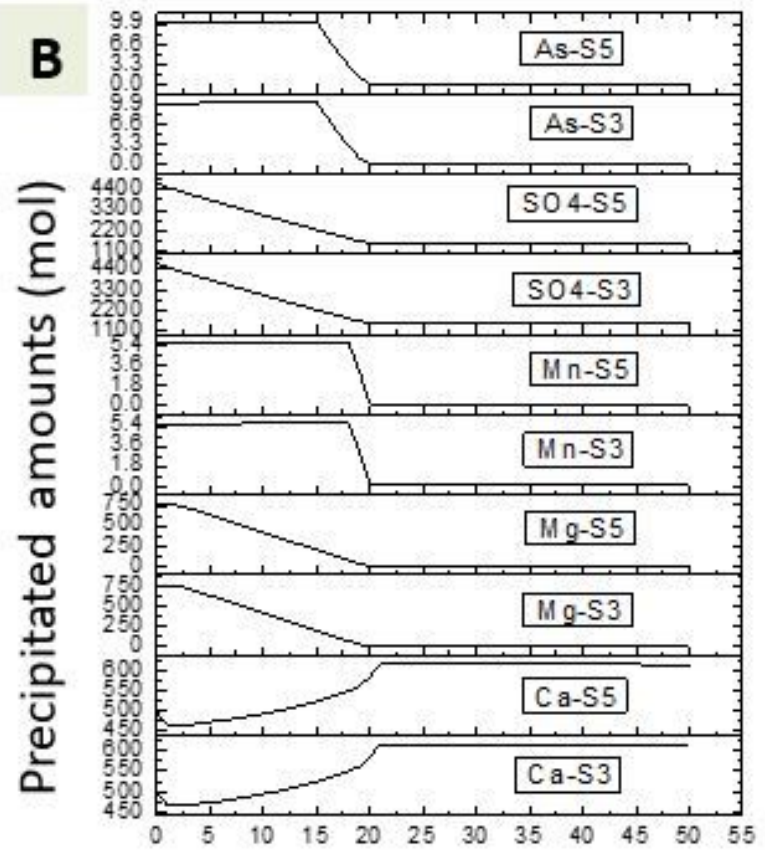

Number of additions

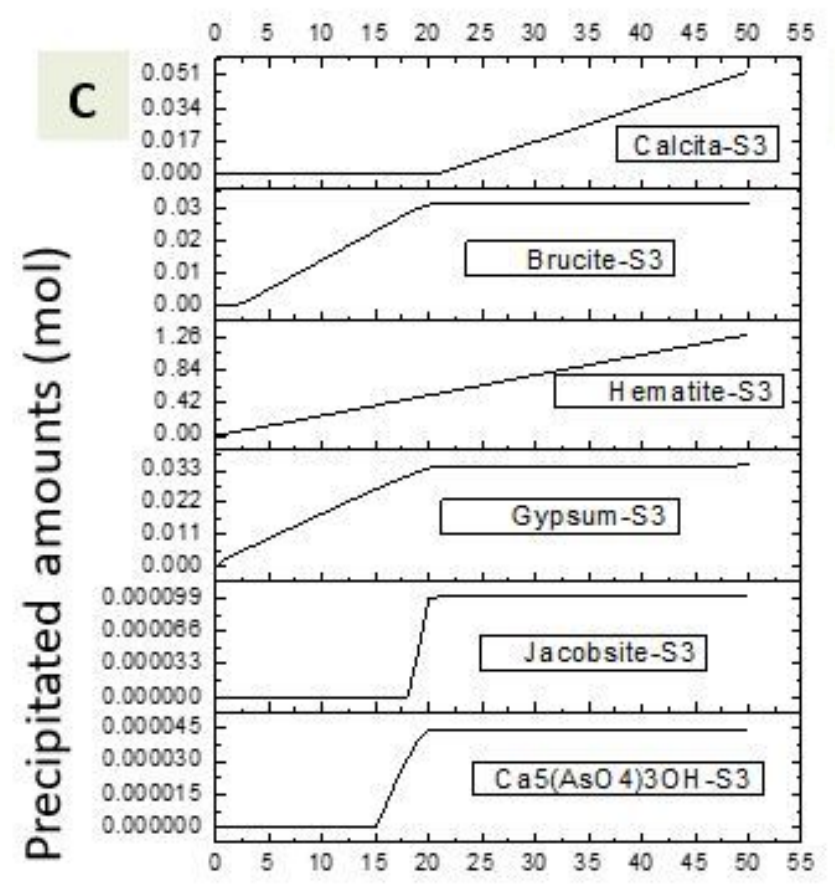

Number of additions

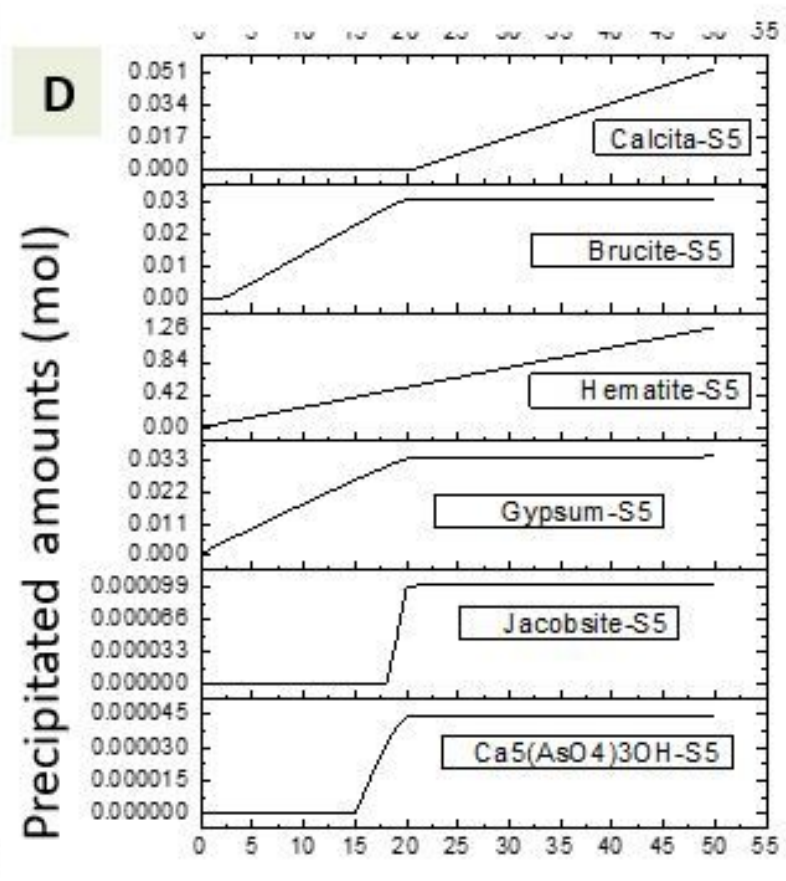

Number of additions

\section{Figure 7}

Graphical representation of the conditions proposed in the modeling by PHREEQC using PHREEQC_ThermoddemV1.10_06Jun2017.dat database (Blanc et al. 2012). 


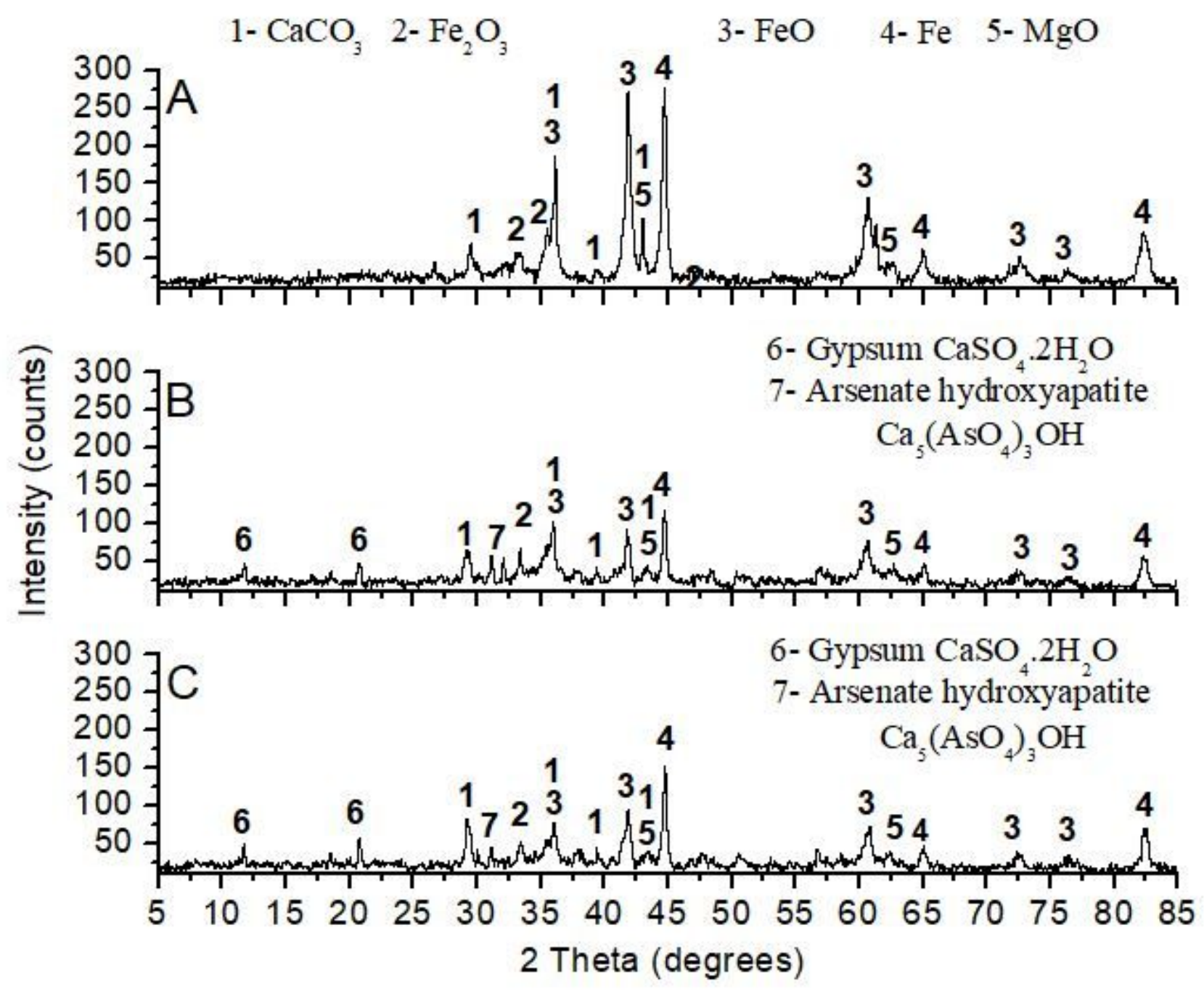

Figure 8

XRD patterns of (A) raw BOFS , (B) BOFS/AMD, and (C) BOFS/AMD/H2O2 $1 \mathrm{mM}$. 


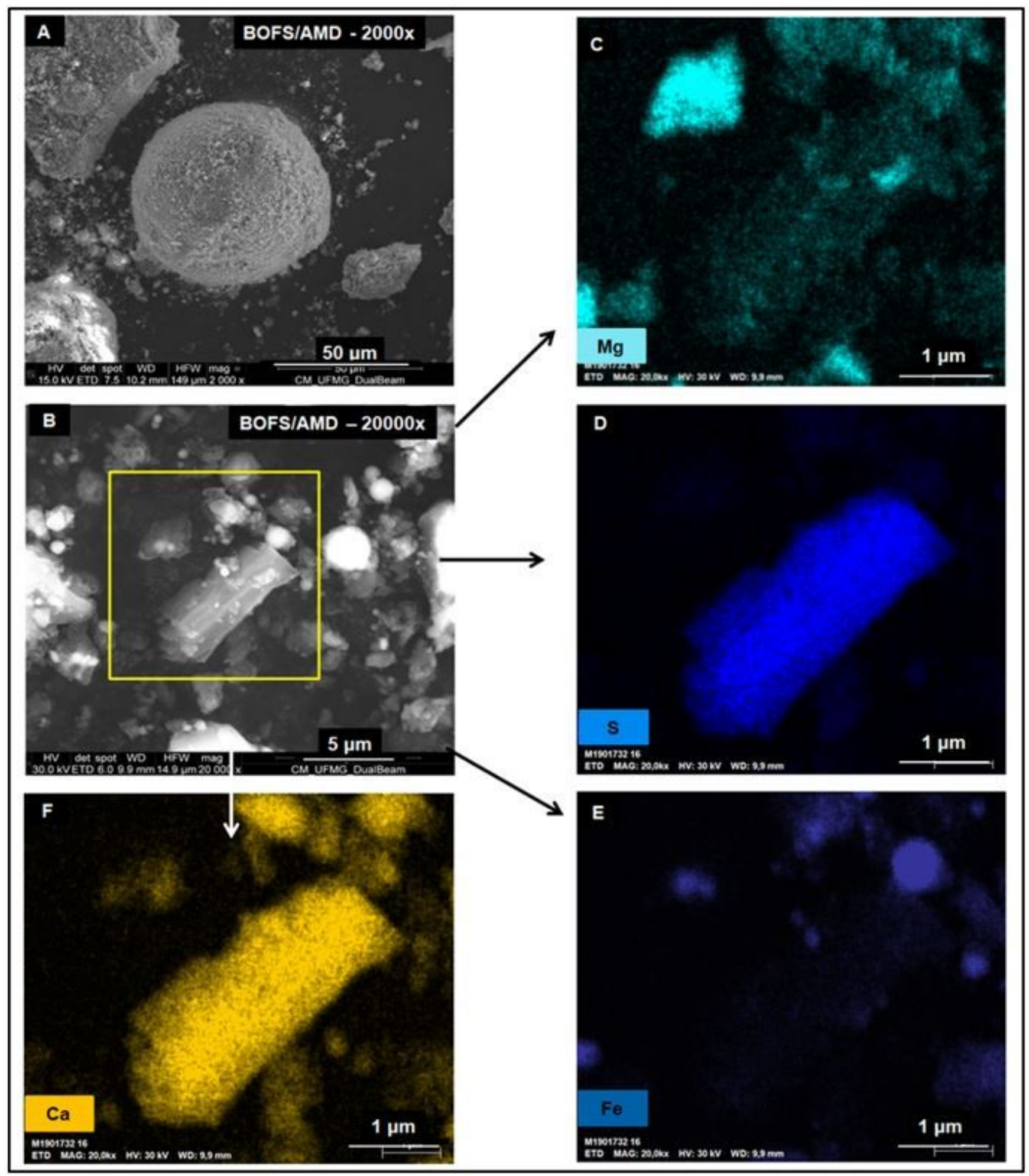

Figure 9

SEM image of (A) BOFS (2000x) and (B) BOFS (20000x). Highlighted area indicates where EDS was analyzed. (C, D, E, F) Corresponding chemical mappings obtained by EDS.

\section{Supplementary Files}


This is a list of supplementary files associated with this preprint. Click to download.

- 0000000155385292supplementarymaterial.docx 